\title{
Thinning behavior of laminated sheets metal in warm deep-drawing process under various grain sizes
}

\author{
Mehran Kadkhodayan ${ }^{\mathrm{a}}$ and Ehsan Afshin \\ Department of Mechanical Engineering, The Ferdowsi University of Mashhad, Mashhad, Iran
}

\begin{abstract}
The purpose of present research is to investigate the thickness distribution on the warm deep-drawing process of laminated sheets consisting of aluminum alloy series 1050, 5052 and stainless steel 304 (SUS), experimentally. Individually for each layer, the influences of blank temperature and grain size on thinning behavior are clearly demonstrated. In order to survey the thinning behavior in laminate sheet behavior during warm deepdrawing process; three blank temperatures namely, $25^{\circ} \mathrm{C}, 100^{\circ} \mathrm{C}$ and $160^{\circ} \mathrm{C}$ are examined. Moreover, to obtain different grain sizes, the aluminum sheets are annealed at $350^{\circ} \mathrm{C}, 400^{\circ} \mathrm{C}$ and $450^{\circ} \mathrm{C}$ for 1 hour. Results indicate that increasing temperature and grain size lead to maximum thinning in all layers in Al 1050/SUS and Al 5052/SUS specimens increase. In addition, the most susceptible zone to fracture in aluminum sheets ( $\mathrm{Al} 1050$ and $\mathrm{Al}$ 5052) is punch profile radius region; nevertheless, for stainless steel sheets this zone switch to central zone of formed cup. These can be attributed to the fact that the adhesive layer play a crucial role in thickness distribution of steel 304 layer, therefore the distribution of thickness strain for adhesive layer is also investigated.
\end{abstract}

\section{Introduction}

Nowadays, the warm deep-drawing process is used extensively because of their application advantages such as manufacturing of complex shape, improved formability, reduced production time and controlled plastic flow. The temperature has significant effect on the material behavior during process and accuracy of finished parts. Moreover, due to wide range of application and unique characteristics of laminated sheets such as; high strength, low density, damping covering structures and corrosion resistibility researchers have been paying more attention to laminated sheets. Consequently, they are used in various industrial fields such as aerospace, automobile, chemical and electrical industries. The laminated sheets formed by warm deep-drawing process can be utilized in manufacturing of parts with different inner and outer conditions, i.e. corrosion, wear resistance and thermal and electrical conductivities $[1,2]$. In the recent years, numerous researchers have paid more attention to deepdrawing process of laminated sheets [3-5]. Nevertheless, their surveys were confined to processes conducted in room temperature.

It is known that aluminum alloys are favorable for aerospace and automotive industry because of their, (i) excellent high-strength to weight ratio, (ii) superior corrosion resistance, (iii) high weldability, and (iv) recyclability. Furthermore, stainless steel sheets are extensively used for manufacturing various parts in the kitchen, vessels, transformation, etc., because of their

\footnotetext{
a Mehran Kadkhodayan: kadkhoda@um.ac.ir
}

high corrosion-resistivity and proper appearance. Warm deep-drawing for aluminum alloy has already been dealt with by many scholars [6-8]. Ethiraj and Kumar surveyed the St 304 deep-drawing process through finite element simulation [9] and empirical observation [10].

The most commonly observed defects in deepdrawing process are thinning, fracture and wrinkling of the material. Thinning and fracture are directly related to part performance and safety. Additionally, annealing and grain size are significant factors in deep-drawing to improve the quality of product, formability, wrinkle pattern, forming load, limit drawing ratio and forming limit diagram (FLD). The grain size is strongly reliant on annealing and re-crystallization. Furthermore, the effect of cold rolling is modified by heat treatment; therefore, properties of metal are changed. Sherbiny et al. [11] clarified the influences of punch and die radii on thinning and residual stresses of sheet metal in the deepdrawing process experimentally. Thinning, thickness distribution and spring back of sheet metal on deepdrawing process successfully were predicted by Zein et al. [12]. Zoesch et al. [13] detected thinning and crack of material during deep-drawing process.

The objective of present work is to investigate the thickness distribution of laminated sheets in warm deepdrawing process. In addition, effect of temperature, grain size (GS) and Blank Holder Force (BHF) on loaddisplacement curves were studied in the authors previous work $[14,15]$. The thickness distribution and fracture zone for each individual layer is also studied in 
the current study. In summary, the objectives are: (1) performance a heat treatment to obtain various grain sizes on aluminum alloys 1050 and 5052, and revelation their microstructures (2) conduction of several tests to observe the effect of grain size on some parameters such as stress and elongation, (3) determination of effect of increasing temperature and grain size on thickness distribution.

\section{Experimental procedures}

\subsection{Warm deep-drawing equipment description}

The scheme of experimental equipment utilized for warm deep-drawing is illustrated in Figure 1. Figure 2 shows the test apparatus which consists of a draw die flange with circular shape, a blank-holder, 8 springs which supply blank-holder force (BHF), punch and heat equipment. Some features of the test rig are shown in Table 1. MO40 steel and SPK steel with appropriate mechanical properties and hardening treatments are used for the materials of the punch and die, respectively. Two annular electrical heaters with a power of $1400 \mathrm{~W}$ are utilized to raise the temperature and the required time to reach the temperature of $160^{\circ} \mathrm{C}$ is about $30 \mathrm{~min}$. According to the tool design, the annular electrical heaters are placed on outer circumference of drawing die and blank-holder. The heaters warm the drawing die and blank-holder; therefore, the blank is heated, even though it has no direct contact with the heaters. A thermocouple is placed in a die, and a digital thermostat with the precision of $1^{\circ} \mathrm{C}$ controls the temperature. A hydraulic press with a maximum load capacity of 60 tons and a punch speed of $540 \mathrm{~mm} / \mathrm{min}$ is used for this process.

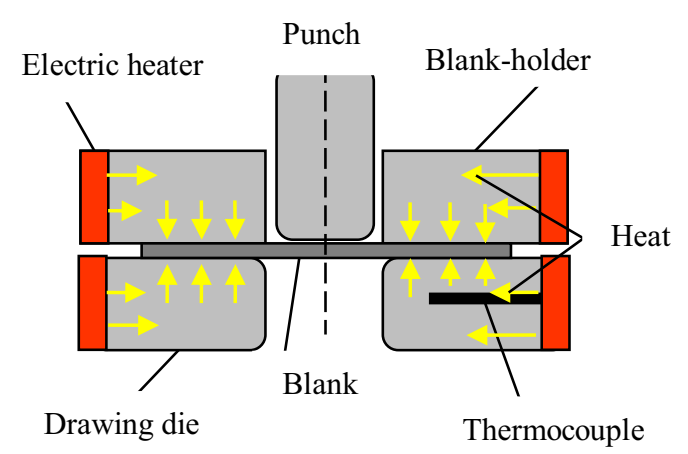

Figure 1. Schematic representation of the equipment for the deep-drawing test.

\subsection{Material and specimen preparation}

The materials of layers used in this process are stainless steel 304 (SUS), aluminum alloys 1050 and 5052 with the chemical compositions as given in Table 2. Two grades of aluminum alloys of 1050 and 5052 are combined with stainless steel 304 to make two various types of laminated sheets (Al 1050/SUS and Al 5052/SUS). Taking forming load, die diameter and drawing depth into account, the optimal diameter of the samples is selected as $132 \mathrm{~mm}$, and thicknesses for aluminum alloys 1050 and 5052 and stainless steel 304 are as $0.8,1$ and $0.4 \mathrm{~mm}$, respectively. Loctite 5368 adhesive is utilized to stick the sheets together due to some advantages such as (i) high flexibility, (ii) medium to high initial strength (iii) and high heat resistant up to $300^{\circ} \mathrm{C}$. Some of the mechanical properties of Loctite 5368 adhesive based on the technical data sheet are presented in Table 3 [16]. In addition, the adhesive layer is uniformly distributed between sheets layer by rig press. Ultimate thickness for Al 5052/SUS and Al 1050/SUS specimen become 2.2 and $2 \mathrm{~mm}$, respectively. Figure 3 exhibits specimen after forming. In all the samples, aluminum sheets are set as upper layer to be in contact with punch and stainless steel sheets are set as lower layer in contact with drawing die. Moreover, process performed in dry condition.

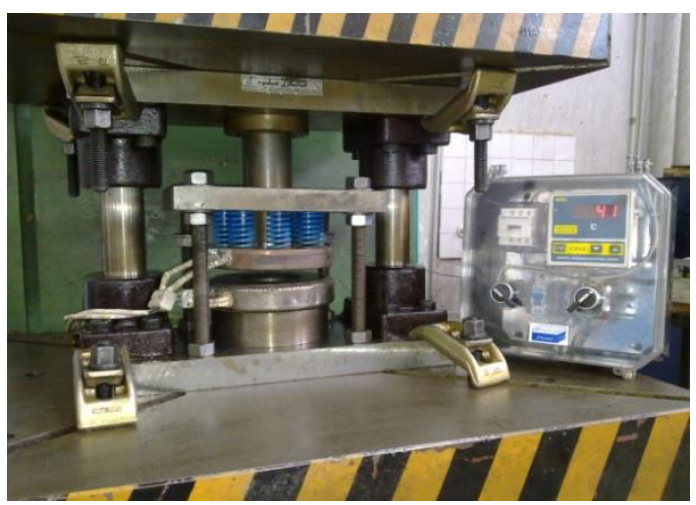

Figure 2. Experimental test equipment.

Table 1. Dimensions of various parts of the deepdrawing die set.

\begin{tabular}{cc}
\hline Dimension & Value (mm) \\
\hline Punch diameter & 65.5 \\
Die inner diameter & 70 \\
Die outer diameter & 153.5 \\
Punch and die profile & 5 \\
Blank-holder inner & 67 \\
Blank-holder outer & 164 \\
Clearance & 2.25 \\
\hline
\end{tabular}

\subsection{Annealing}

One of the noticeable factors in forming process is grain size (GS). Influence of grain size on parameters such as flow stress, machining, friction coefficient and electrical properties are undeniable. Hence, specimens are annealed at $350^{\circ} \mathrm{C}, 400^{\circ} \mathrm{C}$ and $450^{\circ} \mathrm{C}$ for 1 hour, and then cooling process is performed within the furnace for 24 hours. In order to measure the grain size, samples are etched by ( $50 \mathrm{ml}$ Poulton reagent, $25 \mathrm{ml} \mathrm{HNO}_{3}, 40 \mathrm{ml}$ of solution of $3 \mathrm{gr}$ chromic acid per $10 \mathrm{ml}$ of $\mathrm{H}_{2} \mathrm{O}$ ) etchant. The excellent resolution of individual grains and microstructure of $\mathrm{Al} 5052$ and $\mathrm{Al} 1050$ are revealed by Polarized Light Microscope (PLM), see Figures 4 
and 5. The PLM microstructure results indicated that the crystallization has taken place for all samples.

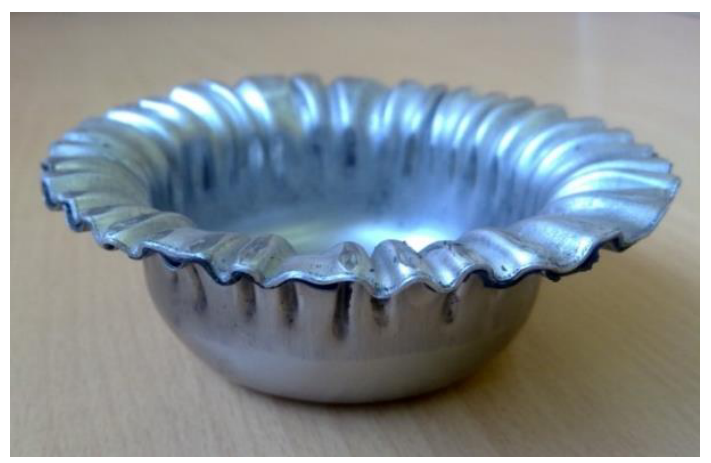

Figure 3. Sample of laminated sheet after forming.

Table 2. Chemical composition (wt. \%) of aluminum alloys and stainless steel.

\begin{tabular}{cccc}
\hline Element & Al 1050 & Al 5052 & St 304 \\
\hline $\mathrm{Si}$ & 0.12 & 0.25 & 0.44 \\
$\mathrm{Fe}$ & 0.28 & 0.40 & 70.55 \\
$\mathrm{Cu}$ & 0.02 & 0.10 & 0.14 \\
$\mathrm{Mn}$ & 0.02 & 0.10 & 1.38 \\
$\mathrm{Mg}$ & 0.02 & 2.82 & - \\
$\mathrm{Zn}$ & 0.011 & 0.10 & - \\
$\mathrm{Ti}$ & - & 0.15 & - \\
$\mathrm{Cr}$ & - & 0.10 & 19.97 \\
$\mathrm{Al}$ & 99.49 & 95.98 & - \\
$\mathrm{V}$ & - & - & 0.12 \\
$\mathrm{Ni}$ & - & - & 7.00 \\
\hline
\end{tabular}

\subsection{Tensile test and flow stress}

To determine the engineering stress-strain behavior of aluminum alloys and St 304 tensile tests are carried out on a Zwick-Z250 uniaxial tensile test machine at room temperature. Tensile samples are prepared to have the dimension with gauge length of $50.0 \mathrm{~mm}$, width of 12.5 $\mathrm{mm}$ based on the ASTM-0557M-02 standard and are cut in the direction of $0^{\circ}$ which conforms directly to the rolling direction. The heat treatment process on aluminums sheets provides various grain sizes for samples which give the possibility to study the influence of grain size on the flow stress. The testing speed has remarkable effect on engineering stress-strain behavior as reported by Rezaei Ashtiani et al. [17]. Their results indicated that magnitude of ultimate stress $\left(\mathrm{S}_{\mathrm{utS}}\right)$ and yield stress $\left(\mathrm{S}_{\mathrm{y}}\right)$, when the grain size increase, depends on testing speed. Based on the punch speed, the tensile tests are carried out with testing speed of $0.002(1 / \mathrm{S})$. The engineering stress-strain curves for $\mathrm{Al}$ 1050, Al 5052 and St 304 are shown in Figure 6.
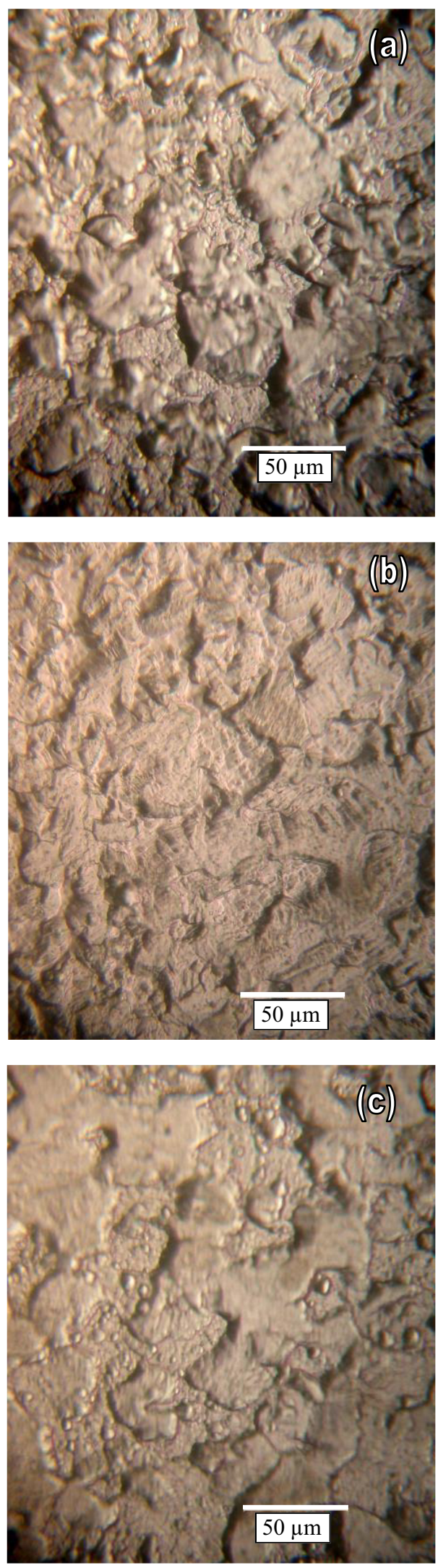

Figure 4. PLM microstructure of $\mathrm{Al} 5052$ specimen with three annealing temperatures of (a) $350^{\circ} \mathrm{C}$, (b) $400^{\circ} \mathrm{C}$ and (c) $450^{\circ} \mathrm{C}$. 

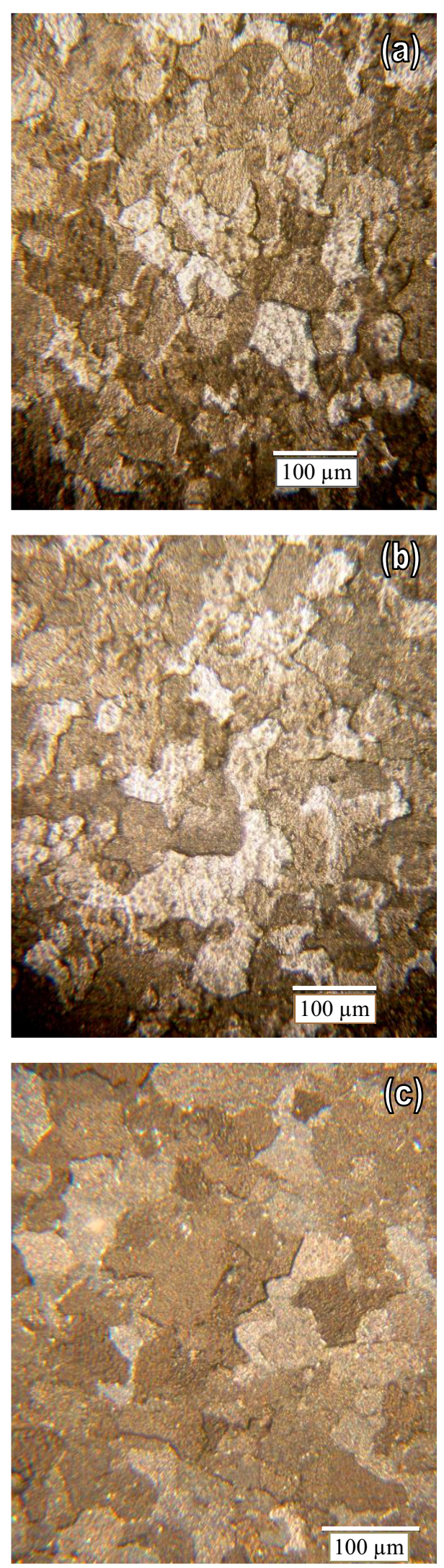

Figure 5. PLM microstructure of $\mathrm{Al} 1050$ specimen with three annealing temperatures of (a) $350^{\circ} \mathrm{C}$, (b) $400^{\circ} \mathrm{C}$ and (c) $450^{\circ} \mathrm{C}$.
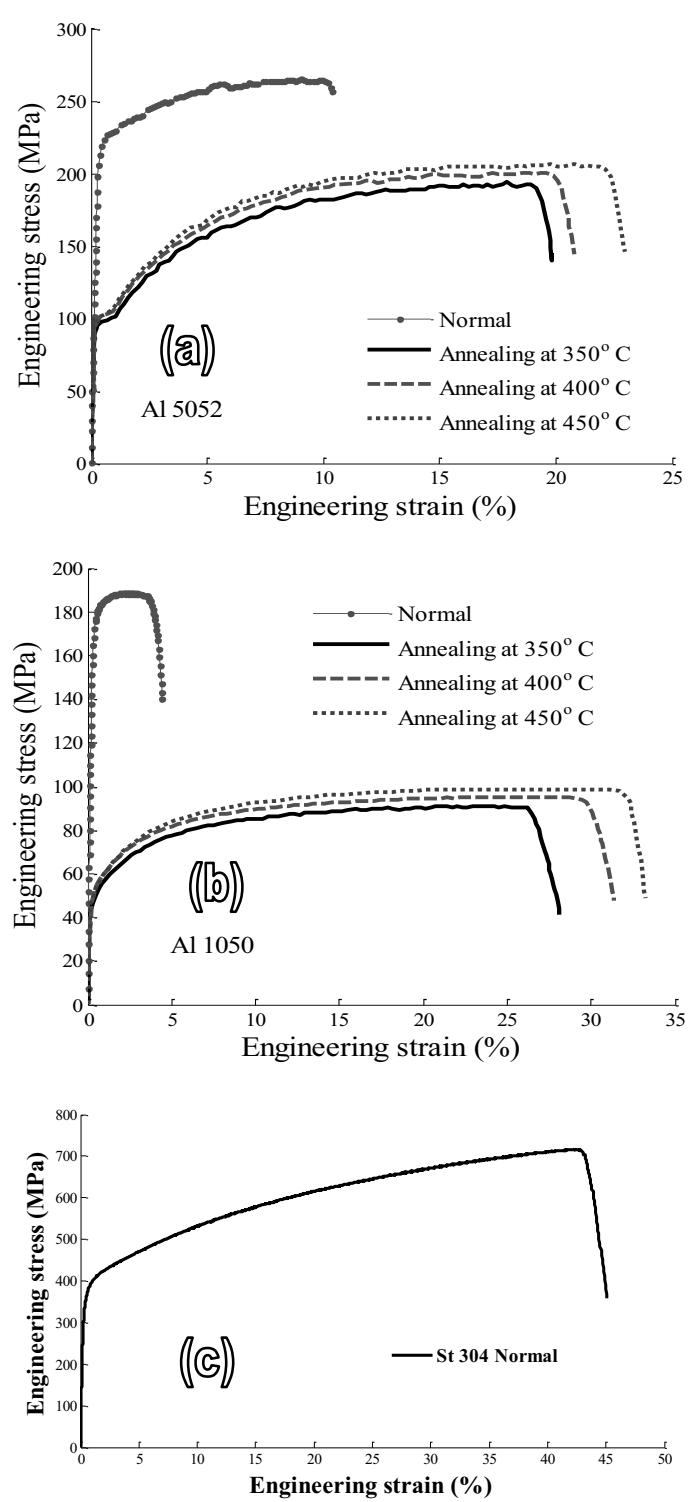

Figure 6. Engineering stress-strain behavior for (a) $\mathrm{Al}$ 5052, (b) Al 1050 and, (c) St 304.

\section{Results and discussion}

\subsection{Effect of annealing on grain size and mechanical properties}

According to the PLM microstructure for Al 5052 and Al 1050, it can be concluded that re-crystallization of aluminum alloys 5052 and 1050 occurred in the $350^{\circ} \mathrm{C}$, for all samples. The grain sizes are measured based on the ASTM-E122-12 standard for different annealing temperatures and are reported in Table 4. Moreover, in Figures 4 and 5 effects of annealing on microstructure and grain size are illustrated. Results indicate that the grain size in Al 1050 and 5052 rise when annealing temperatures increase. Furthermore, the results of engineering stress-strain curves demonstrate that elongation, yield stress and ultimate stress rise with increasing the grain size, Table 5. 
Table 3. Mechanical properties for Loctite 5368 adhesive.

\begin{tabular}{ccc}
\hline Temperature & Tensile Strength (MPa) & Elongation (\%) \\
\hline $25^{\circ} \mathrm{C}$ & 2.2 & 435 \\
$100^{\circ} \mathrm{C}$ & 0.54 & 450 \\
$150^{\circ} \mathrm{C}$ & 0.32 & 580 \\
\hline
\end{tabular}

Table 4. Grain size for aluminum alloys.

\begin{tabular}{ccc}
\hline $\begin{array}{c}\text { Annealing } \\
\text { Temperature }\end{array}$ & $\begin{array}{c}\text { GS for Al 5052 } \\
(\boldsymbol{\mu m})\end{array}$ & $\begin{array}{c}\text { GS for Al 1050 } \\
(\boldsymbol{\mu} \mathbf{m})\end{array}$ \\
\hline $350^{\circ} \mathrm{C}$ & 10 & 37 \\
$400^{\circ} \mathrm{C}$ & 12 & 40 \\
$450^{\circ} \mathrm{C}$ & 14 & 44 \\
\hline
\end{tabular}

Table 5. Mechanical properties for (a) A1 5052 and, (b) Al 1050.

(a) Al 5052

\begin{tabular}{cccc}
\hline Type & $\boldsymbol{S}_{\boldsymbol{y}}$ & $\boldsymbol{S}_{\boldsymbol{u t s}}$ (MPa) & $\begin{array}{c}\text { Elongation } \\
(\mathbf{\%})\end{array}$ \\
\hline Normal & 223.8 & 266.5 & 10.37 \\
Annealing at $350^{\circ} \mathrm{C}$ & 98.2 & 193.9 & 19.8 \\
Annealing at $400^{\circ} \mathrm{C}$ & 101.2 & 200.8 & 20.7 \\
Annealing at $450^{\circ} \mathrm{C}$ & 102.1 & 206.8 & 23 \\
\hline
\end{tabular}

(b) Al 1050

\begin{tabular}{cccc}
\hline Type & $\boldsymbol{S}_{\boldsymbol{y}}$ (MPa) & $\boldsymbol{S}_{\boldsymbol{u t s}}$ (MPa) & $\begin{array}{c}\text { Elongation } \\
\mathbf{( \% )}\end{array}$ \\
\hline Normal & 173.1 & 189.2 & 4.5 \\
Annealing at $350^{\circ} \mathrm{C}$ & 46.4 & 91.2 & 28.1 \\
Annealing at $400^{\circ} \mathrm{C}$ & 48.3 & 95.1 & 31.2 \\
Annealing at $450^{\circ} \mathrm{C}$ & 49.1 & 98.5 & 33.3 \\
\hline
\end{tabular}

\subsection{Thinning}

\subsubsection{Effect of blank temperature on thinning}

One of the most significant factors in warm deepdrawing process is effect of blank temperature on thickness distribution in final product. Hence, for $\mathrm{Al}$ 5052/SUS and Al 1050/SUS samples, thickness strain variations of both layers are determined. Because the thickness variation in circumferential direction is almost symmetrical, it is investigated only diametrically. For this aim, the drawn component is sectioned diametrically by a water jet machine. The thickness of aluminum and stainless steel layer are measured at various positions from the centerline of the component by a micrometer, Figure 7 . Some experiments with different blank temperatures namely, $25^{\circ} \mathrm{C}, 100^{\circ} \mathrm{C}$ and $160^{\circ} \mathrm{C}$ on samples contain $\mathrm{Al} 1050$ and stainless steel 304 are carried out to study the effect of temperature on thinning. The variations of thickness strain for each layer is also determined in the radial direction and are presented in Figures 8 and 9. Maximum thinning for $\mathrm{Al}$ 1050 is taken place at radial distance of about $30 \mathrm{~mm}$ in the region of punch profile radius in all samples. Moreover, the increase in temperature coincides with rising the maximum thinning.

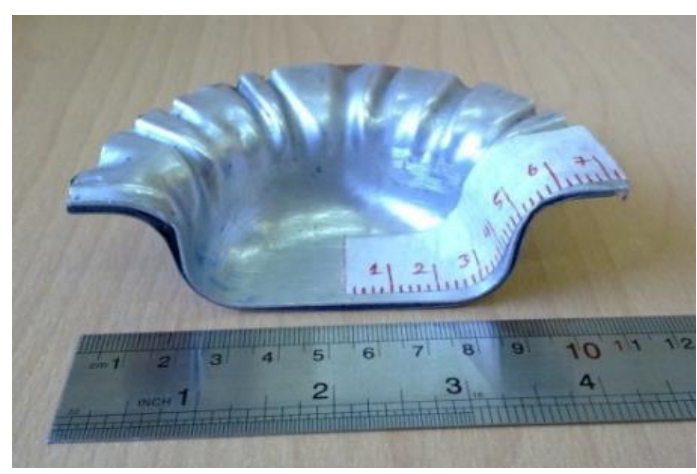

Figure 7. The section formed cup sectioned for evaluation of thickness strain.

Variations of thickness strain for St 304 at Al 1050/ SUS are illustrated in Figure 9. It is seen that the maximum thinning for St 304 increases with raising the temperature. Maximum thinning for St 304 takes place in central region of cup. To show that tearing occurs in the bottom of cup, where significant thickness strain happens; some tests with higher BHF are conducted. One may see an unusual behavior here that tearing occurs in the central area of cup for St 304, see Figure 10 (a). These can be attributed to the function of adhesive layer in thickness distribution of St 304 layer. In fact, radial strain increases when blank temperature rises in the punch profile radius. Hence, the adhesive in this area moves and accumulates in the center area of cup which is especially true in for higher temperatures, and this adhesive movement causes more pressure in the center part. Additionally, the punch acts as a constraint on upper layer (Al 1050) which is not the case in the lower one (St 304). Therefore, rising pressure in the central area of cup has significant effect on thinning of lower layer, and maximum thinning takes place in center area for lower layer (St 304) of cup. To clarify this phenomenon, thickness strain of adhesive layer on sample Al 1050/SUS as an example is illustrated in Figure 11. It is seen that the maximum thickening for adhesive layer occurs at the center of punch. Hence, tearing for St 304 layer takes place at the center of cup. Figure 12 is provided for comparison between thickness strain in all layers in Al 1050/SUS specimen and final cup. It can be concluded that the maximum thickening among all layers corresponds with punch center in adhesive layer, and maximum thinning occurs in the punch radius in adhesive layer.

In continuing, the experiments are carried out on specimen of Al 5052/SUS. Generally, thickness distribution of $\mathrm{Al} 5052 / \mathrm{SUS}$ in all layers closely resembles to that of Al 1050/SUS. Figure 13 shows the distribution of thickness strain for A1 5052 layer under varying temperatures. The obtained results show that the maximum thinning takes place in the region of punch profile radius and by increasing the temperature the tendency of thinning in this region raises. On the other hand, the variation of thickness strain in the bottom of cup is negligible. 


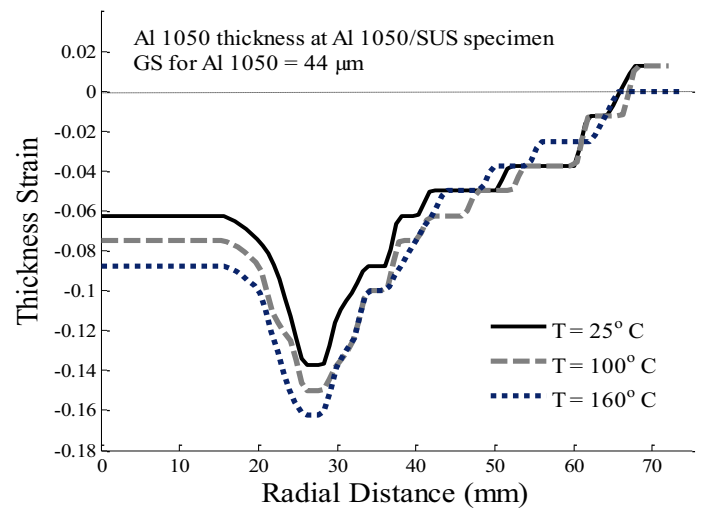

Figure 8. Effect of various temperatures on distribution of thickness strain for $\mathrm{Al} 1050$ layer at $\mathrm{Al}$ 1050/SUS specimen $(\mathrm{BHF}=15 \mathrm{kN})$.

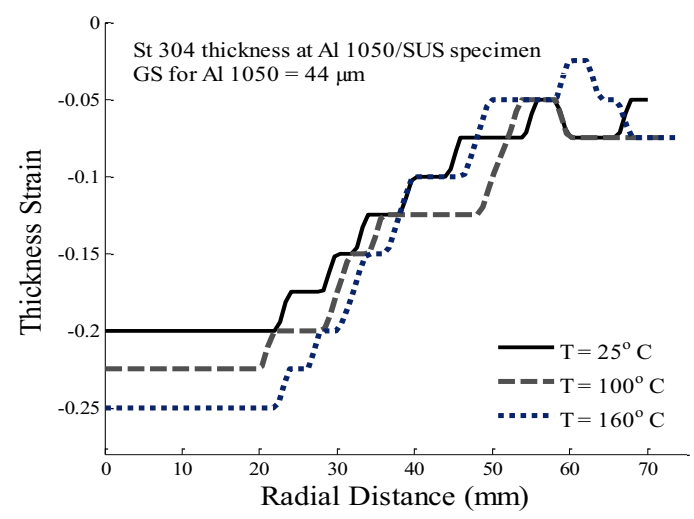

Figure 9. Effect of various temperatures on distribution of thickness strain for St 304 layer at Al 1050/SUS specimen $(\mathrm{BHF}=15 \mathrm{kN})$.

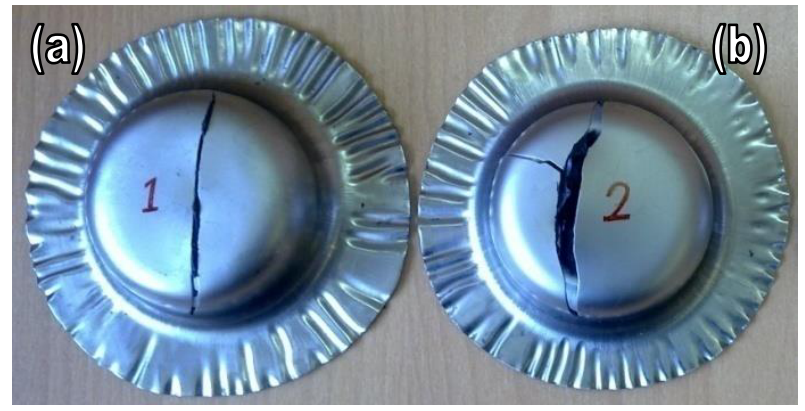

Figure 10. Tearing in the central area of cup for St 304 layer in (a) $\mathrm{Al} 1050 / \mathrm{SUS}$ sample $\left(\mathrm{BHF}=17 \mathrm{kN}, \mathrm{T}=100^{\circ} \mathrm{C}\right)$, and (b) Al 5052/SUS sample $\left(\mathrm{BHF}=19 \mathrm{kN}, \mathrm{T}=100^{\circ} \mathrm{C}\right)$.

Variation of thickness strain for St 304 layer in Al 5052/SUS is illustrated in Figure 14. The thickness distribution of St 304 layer in Al 5052/SUS samples resembles the St 304 layer in Al 1050/SUS specimen in that the maximum thinning occurs in the central area of cup; moreover, raising temperature increase it. In St 304 layer, tearing begins in the central area of cup and as aforementioned it can be attributed to the accumulation of adhesive in central region, Figure 10 (b). Figure 15 shows the distribution of adhesive layer in $\mathrm{Al}$ 5052/SUS. Behavior of thickness strain in adhesive layer indicates that the center of cup has maximum thickening which decreases throughout the punch up to punch profile radius where the maximum thinning of adhesive layer occurs. Figure 16 clearly illustrates the thickness strains for all layers. It is seen that their lowest and highest values correspond to the punch radius and center zone in adhesive layer, respectively.
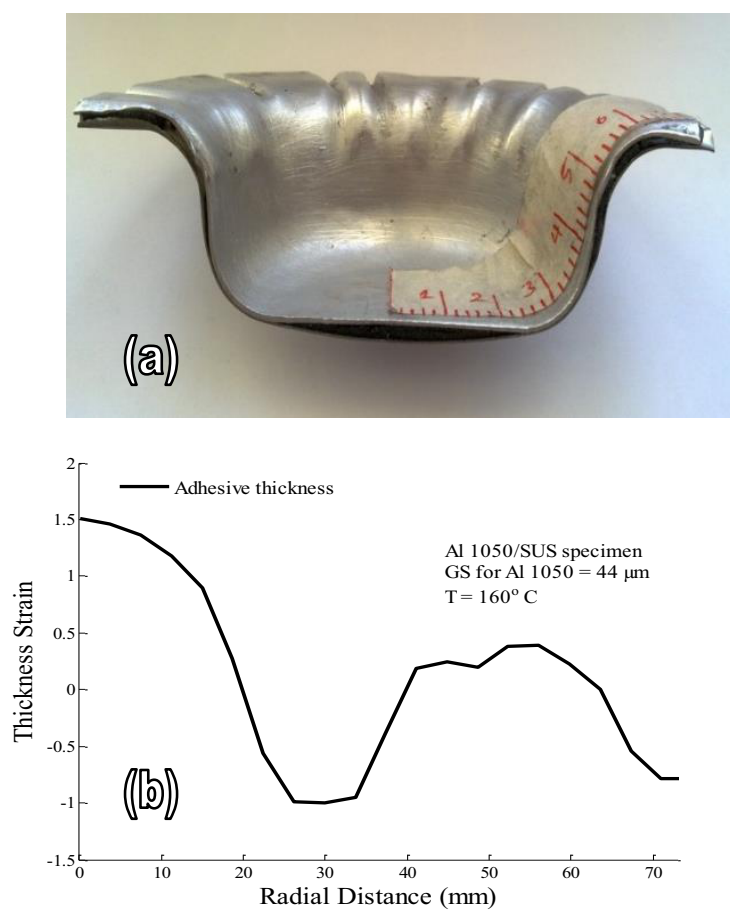

Figure 11. Distribution of thickness strain for adhesive layer at $\mathrm{Al}$ 1050/SUS specimen (GS for $\mathrm{Al} 1050=44$ $\mu \mathrm{m}, \mathrm{T}=160^{\circ} \mathrm{C}, \mathrm{BHF}=15 \mathrm{kN}$ ), (a) real sample, (b) curve of adhesive thickness strain.

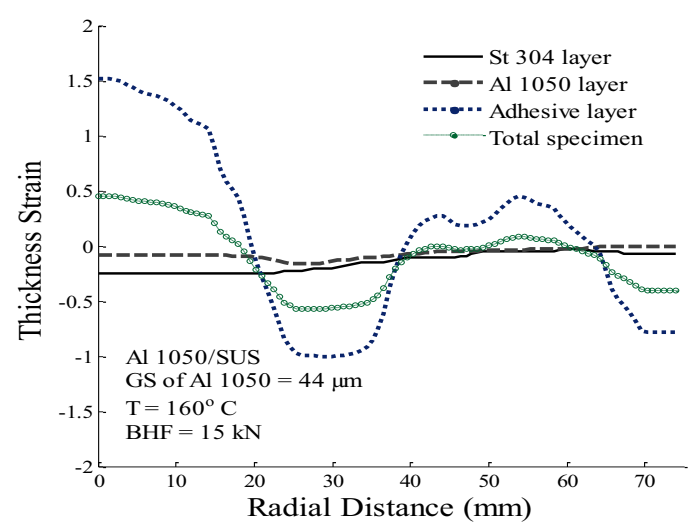

Figure 12. Distribution of thickness strain for all layers and specimen Al 1050/SUS specimen.

\subsubsection{Effect of grain size on thinning}

Effect of various grain sizes on thickness strain of Al 1050/SUS specimens are investigated here. The results indicate that various grain sizes and temperatures have similar effect on strain thickness. Figure 17 represents the influence of different grain sizes of Al 1050 sheet on thickness strain for specimen of Al 1050/SUS. As expected, the punch profile radius zone is susceptible to tearing; because the maximum thinning happens there, 
and this tendency increases with rising grain size of $\mathrm{Al}$ 1050 layer. Moreover, when a material with more elongation is used, the maximum thinning increases (Figure 17). Distribution of thickness strain for St 304 layer in Al 5052/SUS layer shows that the maximum thinning takes place in the central region of cup and increase of thickness strain corresponds to rise of grain size for all specimens, Figure 18. As aforementioned, the distribution of adhesive layer may have the key role here, Figures 11 and 12 .

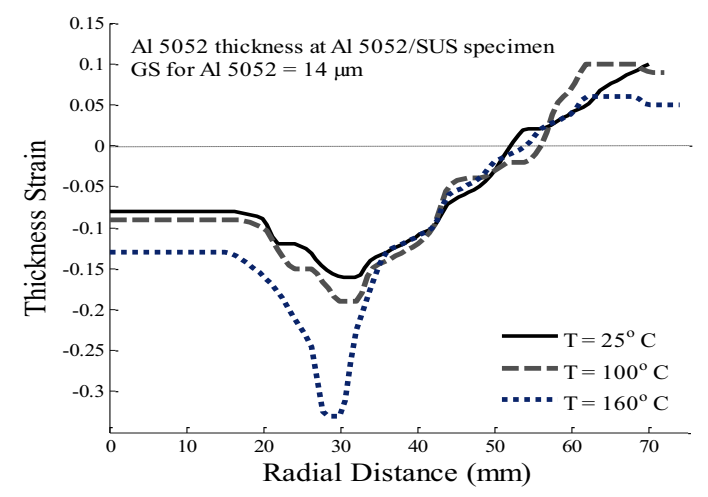

Figure 13. Effect of various temperatures on distribution of thickness strain for Al 5052 layer at Al 5052/SUS specimen $(\mathrm{BHF}=18 \mathrm{kN})$.

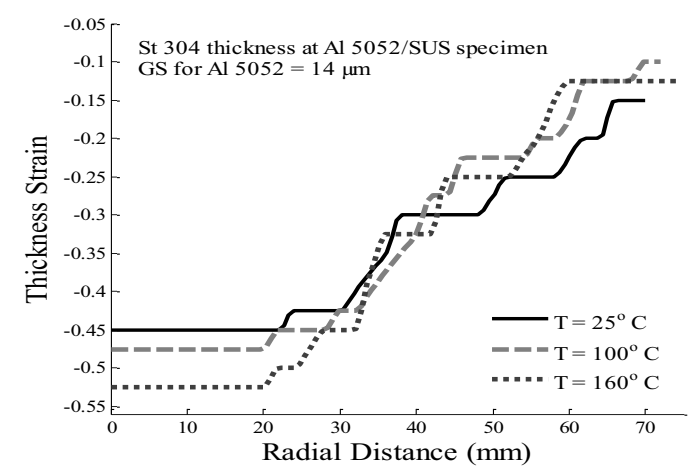

Figure 14. Effect of various temperatures on distribution of thickness strain for St 304 layer at Al 5052/SUS specimen $(\mathrm{BHF}=18 \mathrm{kN})$.

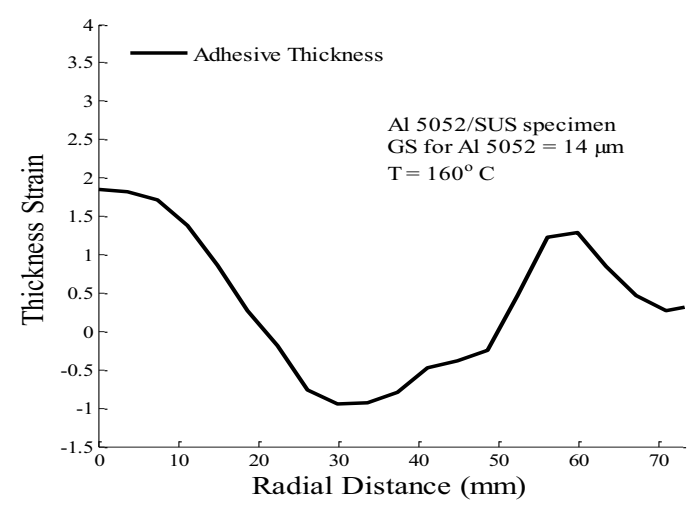

Figure 15. Distributions of the thickness strain for adhesive layer at $\mathrm{Al}$ 5052/SUS specimen (GS for Al 5052 $\left.=14 \mu \mathrm{m}, \mathrm{T}=160^{\circ} \mathrm{C}, \mathrm{BHF}=18 \mathrm{kN}\right)$.

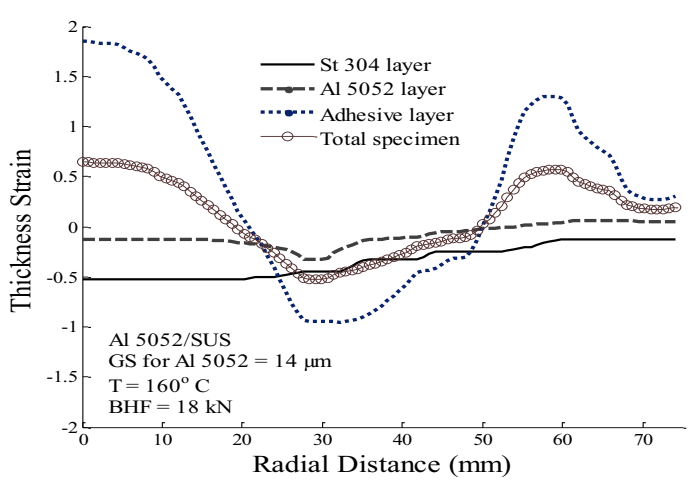

Figure 16. Distributions of the thickness strain for all layers and final specimen $\mathrm{Al}$ 5052/SUS.

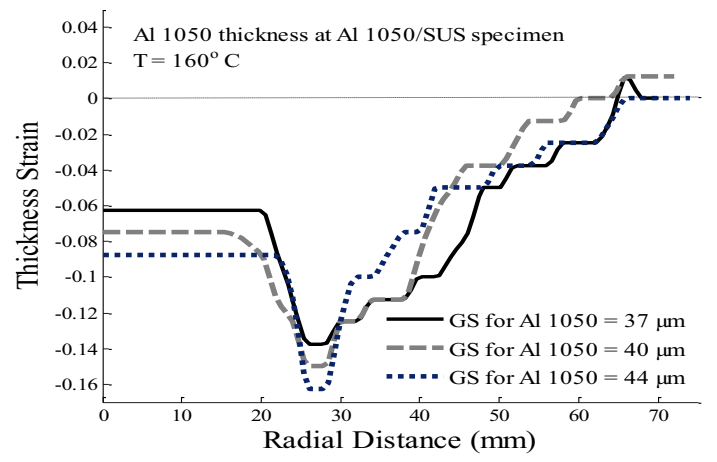

Figure 17. Effect of various grain sizes on distributions of the thickness strain for Al 1050 layer at Al 1050/SUS specimen $(\mathrm{BHF}=15 \mathrm{kN})$.

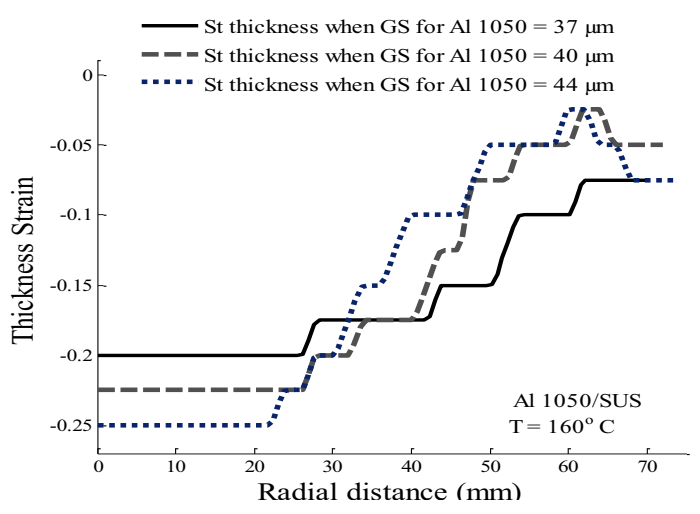

Figure 18. Effect of various grain sizes on distributions of the thickness strain for St 304 layer at Al 1050/SUS.

Finally, the influence of grain size on thickness strain for Al 5052/SUS sample is also investigated. Comparisons of thickness distribution in various grain sizes of Al 5052 and St 304 layer in Al 5052/SUS samples are shown in Figures 19 and 20, respectively. Thickness strain of St 304 layer varies from Al 5052 layer in that the maximum thinning in the former occurs in the central area of cup while in the latter it takes place on the shoulder of cup, especially for the larger grain size. However, increasing of maximum thinning with growth of grain size is clearly visible in both layers. 


\section{Conclusions}

To provide guidelines and to extend fundamental understanding of warm deep-drawing process on laminated sheets, some experimental tests were conducted. The effects of temperature and grain size as main factors on thinning for each layer were investigated under various conditions. In addition, tearing and adhesive behavior were surveyed. The behaviors of Al 1050/SUS and Al 5052/SUS specimen under various conditions were almost similar. In summary, the most remarkable obtained results are as followings.

- Recrystallization occurs at the lowest studied temperature of $350^{\circ} \mathrm{C}$ for aluminum sheets. Moreover, increasing annealing temperature causes higher elongation, ultimate stress, yield stress and grain size.

- Distribution of thickness strain indicates that increasing temperature and grain size lead to maximum thinning rises in all layers in Al 1050/SUS and $\mathrm{Al}$ 5052/SUS specimens.

- The most susceptible areas to fracture in aluminum and stainless steel sheets are at the punch profile radius and central area of cup, respectively.

- Adhesive layer has notable effect on rupture in St 304 layers. Furthermore, the highest thinning and thickening takes place on punch radius and central area of cup in adhesive layer.

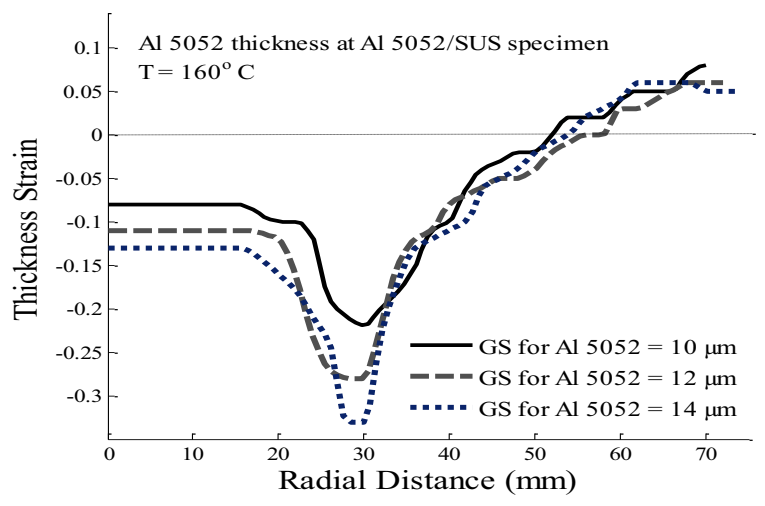

Figure 19 Effect of various grain sizes on distributions of the thickness strain for $\mathrm{Al} 5052$ layer at $\mathrm{Al} 5052 / \mathrm{SUS}$ specimen $(\mathrm{BHF}=18 \mathrm{kN})$.

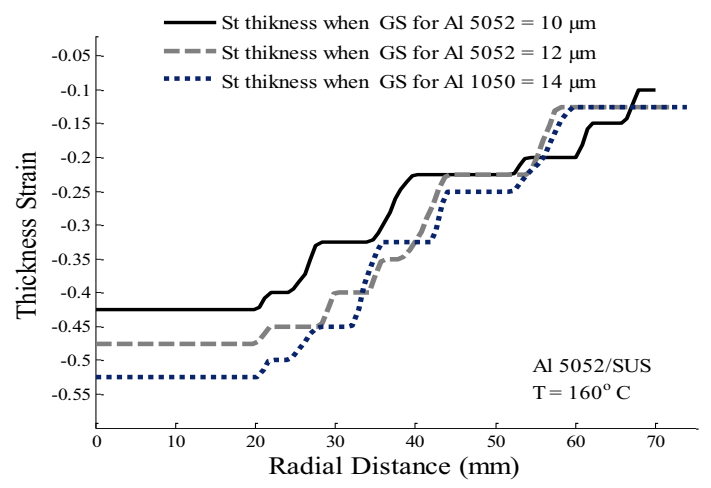

Figure 20. Effect of various grain sizes on distributions of the thickness strain for St 304 layer at $\mathrm{Al}$ 5052/SUS specimen $(\mathrm{BHF}=18 \mathrm{kN})$.

\section{References}

1. S. Bagherzadeh, B. Mollaei-Darianib, K. Malekzadehc, J. Mater. Process. Technol 212, 1840 (2012)

2. F. Stachowicz, T. Trzepieciński, T. Pieja, Arch. Civ. Mech. Eng 10, 85 (2010)

3. M.H. Parsa, K. Yamaguchi, N. Takakura, Int. J. Mech. Sci 43, 2331 (2001)

4. A. Atrian, F. Fereshteh-Saniee, Compos. Part B 47, 75 (2013)

5. A. Rajabi, M. Kadkhodayan, M. Manoochehri, R. Farjadfar, J. Mater. Process. Technol 215, 159 (2015)

6. P. Bolt, N. Lamboo, P. Rozier, J. Mater. Process. Technol 115, 118 (2001)

7. H.S. Kim, M. Koç, J. Ni, J. Mater. Process. Technol 197, 393 (2008)

8. G. Palumbo, L. Tricarico, J. Mater. Process. Technol 184, 115 (2007)

9. N. Ethiraj, V. Kumar, Procedia. Eng 38, 1836 (2012)

10. N. Ethiraj, V. Kumar, Appl. Mech. Mater 26, 436 (2010)

11. M. El Sherbiny, H. Zein, M. Abd-Rabou, Mater. Des 55, 869 (2014)

12. H. Zein, M. El Sherbiny, M. Abd-Rabou, Mater. Des 53, 797 (2014)

13. A. Zoesch, T. Wiener, M. Kuhl, Procedia. CIRP 33, 179 (2015)

14. M. Kadkhodayan, E. Afshin, $F T$ F 2014, 8 (2014)

15. E. Afshin, M. Kadkhodayan, Mater. Des 87, 25 (2015)

16. http://www.loctite.co.uk/homepage.htm, data sheet, (2015)

17. H. Rezaei Ashtiani, M. Parsa, H. Bisadi, Mater. Des 42, 478 (2012) 